\title{
Rhaponticin decreases the metastatic and angiogenic abilities of cancer cells via suppression of the HIF-1 $\alpha$ pathway
}

\author{
AEYUNG KIM and JIN YEUL MA \\ Korean Medicine (KM) Application Center, Korea Institute of Oriental Medicine (KIOM), \\ Daegu 701-300, Republic of Korea
}

Received January 19, 2018; Accepted June 12, 2018

DOI: $10.3892 /$ ijo.2018.4479

\begin{abstract}
Rhaponticin (RA; 3'5-dihydroxy-4'-methoxystilbene $3-O-\beta$-D-glucopyranoside) is a component isolated from various medicinal herbs including Rheum undulatum L. RA has been reported to be an effective treatment for allergy, diabetes, thrombosis, liver steatosis, lung fibrosis and colitis. In addition, RA effectively inhibits tumor growth and induces apoptosis; however, the effects of RA, at non-cytotoxic doses, on the metastasis and angiogenesis of malignant cancer cells have, to be the best of our knowledge, not been identified. In the present study, it was identified that RA suppressed the metastatic potential of MDA-MB231 breast cancer cells, including colony formation, migration and invasion. Human umbilical vein endothelial cells (HUVECs) treated with RA exhibited a decreased ability to form tube-like networks and to migrate across a Transwell membrane, when compared with RA-untreated HUVECs. Using the chick chorioallantoic membrane assay, RA treatment significantly suppressed spontaneous and vascular endothelial growth factor (VEGF)-induced angiogenesis. Furthermore, RA inhibited the production of pro-angiogenic factors, including matrix metalloproteinase (MMP)-9, pentraxin-3, interleukin-8, VEGF and placental growth factor under normoxic and hypoxic conditions, and suppressed the phorbol 12-myristate 13-acetate-induced increase in the gelatinolytic MMP-9 activity and MMP-9 expression in HT1080 cells. RA also significantly inhibited the hypoxia-inducible factor (HIF)-1 $\alpha$ pathway, leading to decreased HIF-1 $\alpha$ accumulation and HIF-1 $\alpha$ nuclear expression under hypoxia. These results indicated that RA exhibits potent anti-metastatic and anti-angiogenic activities with no cytotoxicity via suppression of the HIF-1 $\alpha$ signaling pathway.
\end{abstract}

Correspondence to: Dr Jin Yeul Ma, Korean Medicine (KM) Application Center, Korea Institute of Oriental Medicine (KIOM), 70 Chumdan-ro, Dong-gu, Daegu 701-300, Republic of Korea E-mail: jyma@kiom.re.kr

Key words: rhaponticin, cancer, metastasis, angiogenesis, hypoxiainducible factor $1 \alpha$
Thus, RA may control malignant cancer cells by inhibiting the spread from primary tumors and expansion to distant organs.

\section{Introduction}

Cancer metastasis, the spread of cells from a primary site to distant organs, is an ominous feature of malignant tumors. It is the primary obstacle for effective treatment, and the primary cause of high mortality in patients with cancer $(1,2)$. Metastasis occurs in a series of discrete steps, including the detachment of cells in the primary tumor mass from the extracellular matrix (ECM), invasion to the surrounding tissues, entrance into the lymphatic and blood vessels, survival and migration in the circulation, extravasation into new distant tissues, adaptation to the microenvironment, and final colonization to form a secondary tumor $(3,4)$. This highly complicated process involves proteases including urokinase-type plasminogen activator, cathepsin and matrix metalloproteinases (MMPs), and angiogenic factors including angiogenin, vascular endothelial growth factor (VEGF), platelet-derived growth factor (PDGF) and interleukins, and adhesion proteins including cadherins, integrins and selectins $(2,5)$. Among these components, MMPs have been regarded as critical molecules assisting cancer cells in their progressive proliferation, migration, invasion and angiogenesis. An increase in the expression and proteolytic activity of MMPs in tumors and/or plasma has been positively correlated with rapid progression, metastasis, a high incidence of recurrence and a short survival time (6). In addition, tumors bearing extensive vasculature exhibit increased metastatic potential and become more aggressive tumors $(7,8)$.

Hypoxia is commonly observed in the microenvironment of tumors. Under hypoxic conditions, proteasomal degradation of hypoxia inducible factor (HIF)-1 $\alpha$ is prevented by inactivation of oxygen sensor enzymes including prolyl hydroxylase dehydrogenase and factor inhibiting HIF. In addition, HIF-1 $\alpha$ stabilization, accumulation and translocation into the nucleus are increased, leading to tumor vascularization, metastasis, epithelial-mesenchymal transition (EMT), and resistance to radiation and chemotherapy (9-11). MMPs and the HIF pathway are therefore considered valuable markers and potential therapeutic targets for the control of malignant tumors.

Rheum undulatum $\mathrm{L}$. is a perennial herb that is widely distributed in Asia, including China and Korea. Its pharmacological component is mainly present in the roots. 
R. undulatum $\mathrm{L}$. has been traditionally used as a purgative, laxative, anti-inflammatory and anti-blood stagnation agent in eastern Asia, and has been used to treat dental disease in Korea. Chemical components isolated from $R$. undulatum L., including rhein, emodine, chrysophanol, physicon, resveratrol and rhapontigenin, have been reported to possess anti-allergic, antioxidant, platelet aggregation, antidiabetic and antitumor activities (12-16). Rhaponticin (RA; 3'5-dihydroxy4'-methoxystilbene 3-O- $\beta$-D-glucopyranoside; Fig. $1 \mathrm{~A}$ ) from $R$. undulatum L. has been identified to exhibit beneficial effects, including anti-allergic, anti-diabetic and anti-thrombotic activities $(14,17)$. Furthermore, RA effectively alleviated colitis, pulmonary fibrosis and liver steatosis (18-20); however, to the best of our knowledge, the effects of RA on metastasis and angiogenesis in cancer cells have not been identified.

In the present study, the effects of RA on the metastatic and angiogenic properties of cancer and endothelial cells were investigated using an in vitro assay and an in ovo chick chorioallantoic membrane (CAM) assay. In addition, the underlying molecular mechanisms of its anti-metastatic and anti-angiogenic activities were investigated.

\section{Materials and methods}

Cells and culture. Human breast adenocarcinoma MDA-MB231 cells [Korean Cell Line Bank (KCLB) no. 30026] and human fibrosarcoma HT1080 cells (KCLB no. 10121) were purchased from the KCLB (Seoul, Korea) and maintained in Dulbecco's modified Eagle's medium (DMEM) or RPMI-1640 medium supplemented with $10 \%$ fetal bovine serum (FBS; Biotechnics Research, Lake Forest, CA, USA) containing $100 \mathrm{U} / \mathrm{ml}$ penicillin and $100 \mu \mathrm{g} / \mathrm{ml}$ streptomycin (Cellgro; Corning Incorporated, Corning, NY, USA) at $37^{\circ} \mathrm{C}$ in a $5 \% \mathrm{CO}_{2}$ incubator. Human umbilical vein endothelial cells (HUVECs; Innopharmascreen, Asan, Korea) were maintained in endothelial cell growth medium-2 (EGM-2; PromoCell $\mathrm{GmbH}$, Heidelberg, Germany) and used at passages 3-8 in the experiments. RA ( $\geq 98 \%$ purity determined using high-pressure liquid chromatography) was obtained from Faces Biochemical (Wuhan, China).

Cell death and colony formation analysis. Cells $\left(5 \times 10^{3}\right.$ cells/ well/100 $\mu \mathrm{l}$ ) were seeded into 96-well culture plates and treated with or without the specified concentrations of RA. After $48 \mathrm{~h}$, the cell viability was determined using the Cell Counting Kit-8 (CCK-8; Dojindo Molecular Technologies, Inc., Kumamoto, Japan). To evaluate the ability to form sizable colonies, cells (1x $10^{3}$ cells/well) seeded into 6-well plates were incubated for 10 days with or without the indicated concentrations of RA. At the end of the experiments, the cells were washed three times with PBS, and the colonies were stained with $0.2 \%$ crystal violet $/ 20 \%(\mathrm{w} / \mathrm{v})$ methanol solution for $30 \mathrm{~min}$. The cells were washed with tap water thoroughly and air-dried, and images were captured. To quantify colony formation, the dye was extracted with dimethylsulfoxide (DMSO) and the absorbance was measured at $590 \mathrm{~nm}$ using a SpectraMaxi3 Multi-mode reader (Molecular Devices, LLC, Sunnyvale, CA, USA).

Scratch and Transwell ${ }^{\circledR}$ migration assays. For the scratch migration assay, cells $\left(2 \times 10^{4}\right.$ cells/well/100 $\left.\mu \mathrm{l}\right)$ were seeded into 96-well plates, allowed to adhere overnight and treated with $25 \mu \mathrm{g} / \mathrm{ml}$ mitomycin (Sigma-Aldrich; Merck KGaA, Darmstadt, Germany) for 30 min. Following the creation of wounds on the confluent monolayers using a 96-pin Wound Maker (IncuCyte; Essen Bioscience, Ann Arbor, MI, USA), the plates were placed into the IncuCyte chamber (Essen Bioscience) and incubated with or without RA in a $5 \% \mathrm{CO}_{2}$ incubator at $37^{\circ} \mathrm{C}$. The wound images were captured every $3 \mathrm{~h}$ using an IncuCyte Zoom system (Essen Bioscience). The wound closure proportion at each time point was calculated based on the wound width at $0 \mathrm{~h}$ as $100 \%$. For the Transwell migration assay, a Transwell chamber $(10 \mathrm{~mm}$ diameter, $8 \mu \mathrm{m}$ pore size polycarbonate membrane; Corning Incorporated) was used. In the lower chamber, $600 \mu 1$ 10\% FBS in DMEM or EGM-2 was used for tumor cells or HUVECs, respectively. In the upper chamber, cells $\left(1 \times 10^{5}\right.$ cells/well $)$ suspended in $100 \mu 1$ serum-free DMEM or endothelial cell basal medium-2 (EBM-2) were added. Following incubation at $37^{\circ} \mathrm{C}$ with $5 \% \mathrm{CO}_{2}$ for $12 \mathrm{~h}$, the migrated cells were fixed, stained with $0.2 \%$ crystal violet $/ 20 \%$ (w/v) methanol solution, and counted using a phase-contrast microscope (magnification, $\mathrm{x} 100$ ).

Scratch, Transwell and three-dimensional (3D) spheroid invasion assays. A scratch wound invasion assay using IncuCyte Zoom and the Transwell invasion assay were used with Matrigel ${ }^{\circledR}$ (BD Biosciences, Franklin Lakes, NJ, USA) diluted 1:4 with serum-free medium as the intervening invasive barrier. In addition, a 3D invasion assay was performed using the Cultrex 96-well 3D Spheroid Cell Invasion assay (Trevigen; Bio-Techne, Minneapolis, MN, USA), according to the manufacturer's protocol. In brief, 3x105 cells were suspended in $50 \mu \mathrm{l}$ prechilled spheroid formation ECM, added to a Corning 96-well Clear Round Bottom Ultra Low Attachment Microplate (Corning Incorporated), centrifuged at $200 \mathrm{x} \mathrm{g}$ for $3 \mathrm{~min}$ at room temperature, and then incubated for 3 days to assemble into compact spheroids. Following the addition of $50 \mu \mathrm{l}$ prechilled invasion matrix, the plates were centrifuged at $300 \mathrm{xg}$ for $5 \mathrm{~min}$ at $4^{\circ} \mathrm{C}$ and incubated for $1 \mathrm{~h}$ at $37^{\circ} \mathrm{C}$ to promote gel formation. Culture medium containing the indicated concentrations of RA was then added into each well and the plates were incubated at $37^{\circ} \mathrm{C}$ in a $5 \% \mathrm{CO}_{2}$ incubator for between 3 and 5 days. Cells that invaded the surrounding matrix were observed using a phase-contrast inverted microscope (magnification, x100) and images were captured every $24 \mathrm{~h}$.

Gelatin zymography. The MMP-9 activity in RA-treated or -untreated HT1080 conditioned medium (CM) was measured by zymography using a gelatin substrate as described previously (21). The activity of gelatinase was detected as a clear band with a blue background at $92 \mathrm{kDa}$. Phorbol 12-myristate 13-acetate (PMA) was obtained from Sigma-Aldrich.

HUVEC tube formation assays. Capillary-like tube formation of endothelial cells was measured using a Cultrex in vitro angiogenesis assay kit (Trevigen; Bio-Techne), according to the manufacturer's protocol. In brief, $50 \mu \mathrm{l}$ basement membrane extract was coated on a prechilled 96-well culture plate and polymerized for $30 \mathrm{~min}$ at $37^{\circ} \mathrm{C}$. RA-treated or untreated HUVECs $\left(5 \times 10^{4}\right)$ suspended in $100 \mu \mathrm{l}$ EGM-2 were added to 
each well and incubated for between 4 and $12 \mathrm{~h}$ at $37^{\circ} \mathrm{C}$. The tube formation was visualized using a phase-contrast inverted microscope (magnification, x100).

Proteome profiler antibody arrays. The expression profile of angiogenesis-associated proteins in the RA-treated or untreated $\mathrm{CM}$ was determined using a Proteome Profiler ${ }^{\mathrm{TM}}$ Human Angiogenesis Array kit (R\&D Systems, Inc., Minneapolis, MN, USA). The blots were visualized using a ChemiDoc ${ }^{\mathrm{TM}}$ Touch Imaging system using a Clarity ${ }^{\mathrm{TM}}$ western enhanced chemiluminescence (ECL) substrate (Bio-Rad Laboratories, Inc., Hercules, CA, USA). For the preparation of CM under hypoxia, the cells were incubated with or without $50 \mu \mathrm{M}$ RA for $24 \mathrm{~h}$ in complete medium, washed with $0.5 \%$ FBS medium three times, and then incubated under hypoxic conditions $\left(1 \% \mathrm{O}_{2}\right)$ for an additional $24 \mathrm{~h}$ in $0.5 \%$ FBS medium. The culture medium was harvested, centrifuged at 13,000 $\mathrm{x}$ g for $15 \mathrm{~min}$ at $4^{\circ} \mathrm{C}$ to remove cell debris, and collected as CM.

Fluorescence immunocytochemistry. Cells were seeded into 35-mm-diameter glass-bottomed dishes (SPL Life Sciences, Pocheon, Korea), treated with RA for $12 \mathrm{~h}$, and then stimulated with $200 \mu \mathrm{M} \mathrm{CoCl}_{2}$ for $6 \mathrm{~h}$. Following washing with ice-cold PBS three times, the cells were subjected to immunocytochemistry as described previously (22). Following counterstaining with DAPI, the cells were analyzed for the nuclear expression of HIF-1 $\alpha$ using a fluorescence microscope (Eclipse Ti; Nikon Corporation, Tokyo, Japan, magnification, x100).

Western blotting. Whole cell lysates were prepared using Mammalian Protein Extraction Reagent (Thermo Fisher Scientific, Inc., Waltham, MA, USA) and the protein concentration was determined using a Bicinchoninic Acid protein assay kit (Pierce; Thermo Fisher Scientific, Inc.). Equal amounts of each samples $(20 \mu \mathrm{g})$ mixed with NuPAGE lithium dodecyl sample buffer (Invitrogen; Thermo Fisher Scientific, Inc.) were denatured by heating for $10 \mathrm{~min}$ at $95^{\circ} \mathrm{C}$ and then separated by SDS-PAGE (8-15\%). Following electrotransfer onto a polyvinylidene difluoride membrane (Immobilon-P; Merck Millipore, Darmstadt, Germany), membranes were blocked in a $3 \% \mathrm{BSA} /$ Tris-buffered saline solution containing $0.05 \%$ Tween-20 (TBST) for $1 \mathrm{~h}$ at $25^{\circ} \mathrm{C}$ and washed three times with TBST. Membranes were incubated with specific antibodies (1:1,000 dilution in 3\% BSA/TBST) overnight at $4^{\circ} \mathrm{C}$, washed three times with TBST, and then incubated with horseradish peroxidase-conjugated secondary antibodies (1:4,000 dilution in $3 \% \mathrm{BSA} / \mathrm{TBST})$ for $1 \mathrm{~h}$ at $25^{\circ} \mathrm{C}$. Following washing three times with TBST, immune-reactive protein bands were detected using a ChemiDoc Touch Imaging system with a Clarity western ECL substrate. The relative band intensity was calculated using ImageJ software (version 1.50; National Institutes of Health, Bethesda, MD, USA). Antibodies against protein kinase B (Akt; cat. no. 4685), phospho (p)-Akt (cat. no. 9271), mammalian target of rapamycin (mTOR; cat. no. 2983), p-mTOR (cat. no. 5536), MMP-9 (cat. no. 2270), von Hippell-Lindau protein (VHL; cat. no. 68547) and tubulin (cat. no. 2125) were obtained from Cell Signaling Technology, Inc. (Danvers, MA, USA), and an anti-HIF-1 $\alpha$ antibody (cat. no. 610958) was obtained from BD Biosciences. The EMT Antibody Sampler kit (cat. no. 9782) including $\beta$-catenin,
Table I. Primers used for the polymerase chain reaction.

\begin{tabular}{ll} 
Target gene & \multicolumn{2}{c}{ Sequence } \\
\hline MMP-9 & F: 5'-CAAGCTGGACTCGGTCTTTGA-3' \\
& R: 5'-TTCAACTCACTCCGGGAACTCA-3' \\
PTX-3 & F: 5'-CATCCAGTGAGACCAATGAGG-3' \\
& R: 5'-GTAGCCGCCAGTTCACCATTT-3' \\
VEGF- $\alpha$ & F: 5'-CCACTGAGGAGTCCAACATCA-3' \\
& R: 5'-CATTTACACGTCTGCGGATCTT-3' \\
PIGF & F: 5'-ACTCAGCTCTTCTCCTCCTGTG-3' \\
& R: 5'-ACGGTAATAAATACACGAGCCG-3' \\
HIF-1 $\alpha$ & F: 5'-AACCACCTATGACCTGCTTGGT-3' \\
& R: 5'-TTGAGCGGCCTAAAAGTTCTTC-3' \\
VHL & F: 5'-TACCGAGGTCACCTTTGGC-3' \\
& R: 5'-GGAGGCATCGCTCTTTCAG-3' \\
GAPDH & F: 5'-TCATGACCACAGTCCATGCC-3' \\
& R: 5'-TCCACCACCCTGTTGCTGTA-3'
\end{tabular}

F, forward; R, reverse; MMP, matrix metalloprotein; PTX-3, pentraxin-related protein 3; VEGF, vascular endothelial growth factor; PIGF, placental growth factor; HIF, hypoxia-induciblefactor; VHL, von Hippell-Lindau protein.

neuronal (N-)cadherin, Slug, Snail, zinc finger E-box-binding homeobox 1 (ZEB1), vimentin, claudin-1 and epithelial (E-) cadherin was purchased from Cell Signaling Technology, Inc.

Reverse transcription-polymerase chain reaction (RT-PCR). Total RNA was extracted from RA-treated or -untreated HT1080 under $\mathrm{CoCl}_{2}$ stimulation and then reverse-transcribed into cDNA using an RNA extraction solution and a First Strand cDNA Synthesis kit (BioAssay Co., Ltd., Daejeon, Korea), respectively, according to the manufacturer's protocol. Amplification of MMP-9, pentraxin-related protein 3 (PTX-3), VEGF- $\alpha$, placental growth factor (PIGF), HIF-1 $\alpha$ and VHL was performed using a Vertiti 96-well Thermal Cycler (Applied Biosystems; Thermo Fisher Scientific, Inc.) using specific primers (Table I). The PCR conditions were as follows: $94^{\circ} \mathrm{C}$ for $3 \mathrm{~min}$ and $25-35$ cycles of $94^{\circ} \mathrm{C}$ for $30 \mathrm{sec}$, $54^{\circ} \mathrm{C}$ for $30 \mathrm{sec}$, and $70^{\circ} \mathrm{C}$ for $30 \mathrm{sec}$, with a final extension of $10 \mathrm{~min}$ at $72^{\circ} \mathrm{C}$. GAPDH was used as a reference gene. PCR products were visualized on a $1 \%$ agarose gel by staining with GreenLight $^{\mathrm{TM}}$ (BioAssay Co., Ltd.) and the relative band intensity was calculated using ImageJ software.

CAM assay. Fertilized chicken eggs purchased from Pulmuone Co., Ltd. (Seoul, Korea) were incubated in a digital egg incubator (MX-190 CD, R-COM, Gimhae, Korea) at $37^{\circ} \mathrm{C}$ with $65 \%$ humidity. The starting time point was designated as the chick embryonic development (ED) day 0. On ED day 3, $3 \mathrm{ml}$ albumin was removed using a syringe and a round window was made in each egg. Following resealing of the windows with adhesive tape, the eggs were returned to the incubator. To investigate the effects of RA on angiogenesis, 5-mm-diameter discs loaded with RA and/or VEGF in $20 \mu \mathrm{l}$ PBS were placed 
A<smiles>COc1ccc(/C=C/c2cc(O)cc(O[C@@H]3O[C@H](CO)[C@@H](O)[C@H](O)[C@H]3O)c2)cc1O</smiles>

Rhaponticin (RA)
B

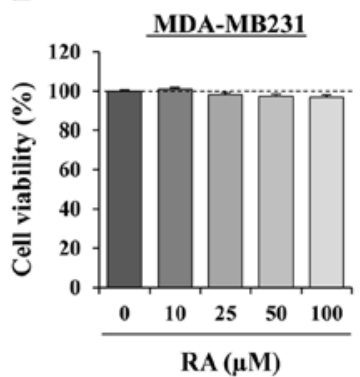

C

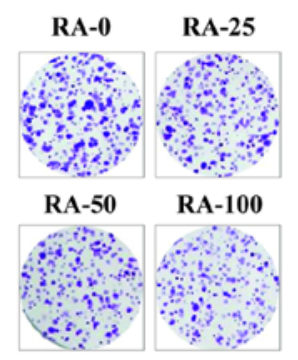

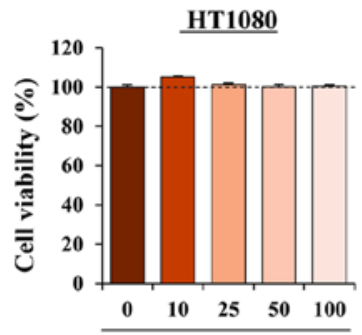

$\mathrm{RA}(\mu \mathrm{M})$

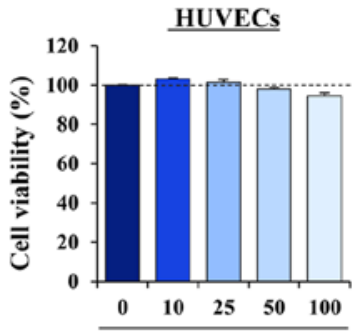

$\mathrm{RA}(\mu \mathrm{M})$

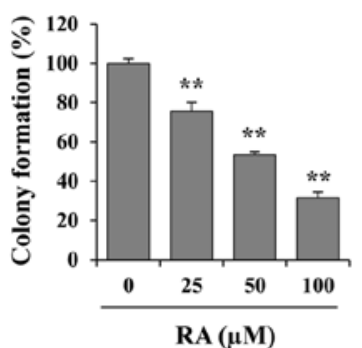

Figure 1. RA exhibits no cytotoxicity and suppresses colony-forming activity in MDA-MB231 cells. (A) Chemical structure of RA. (B) MDA-MB231 cells, HT1080 cells and HUVECs were seeded into 96-well culture plates in triplicate and treated with the indicated concentrations of RA. At $48 \mathrm{~h}$ after treatment, the proportion of viable cells was determined using the Cell Counting Kit-8 assay, then compared with that of RA-untreated cells, and expressed as the mean \pm SD. (C) Anchorage-dependent colony formation of MDA-MB231 cells in the presence or absence of RA was determined by counting visible colonies following staining with crystal violet solution ( $\mathrm{n}=3$ per group). The relative values are expressed as the mean $\pm \mathrm{SD} .{ }^{* *} \mathrm{P}<0.01$ vs. untreated control. $\mathrm{RA}$, rhaponticin; HUVEC, human umbilical vein endothelial cell; SD, standard deviation.

on the CAM of individual embryos on ED day 6. Following incubation for 3 days, the vasculature was observed and images were captured.

Statistics. Results are expressed as the mean \pm standard deviation. Statistical significance of treatment effects were analyzed using one-way analysis of variance (ANOVA) followed by Dunnett's test with GraphPad Prism 5 software (GraphPad Software, Inc., La Jolla, CA, USA). Analysis in two groups was performed using Student's t-test. $\mathrm{P}<0.05$ was considered to indicate a statistically significant difference.

\section{Results}

RA exhibits no cytotoxicity and suppresses anchoragedependent colony formation in MDA-MB231 cells. Prior to assessing the anti-metastatic activity of RA, its cytotoxic effects on cancer and endothelial cells were determined using a CCK-8 assay following incubation of the cells with the indicated doses of RA for $48 \mathrm{~h}$. Since RA was dissolved in $100 \%$ DMSO to a final concentration of $100 \mathrm{mM}, 0.001 \%$ DMSO was used as the vehicle control. Fig. $1 \mathrm{~B}$ indicates that, at concentrations up to $100 \mu \mathrm{M}$, RA did not decrease the cell viability of MDA-MB231 cells, HT1080 cells or HUVECs. In subsequent studies, cells were therefore treated with RA at concentrations of 25, 50 and $100 \mu \mathrm{M}$. Since adhesion and colony formation are essential steps in distant metastasis, the ability of MDA-MB231 cells to form detectable colonies from a single cell in the presence or absence of RA was investigated. Fig. 1C indicates that RA significantly inhibited anchorage-dependent colony formation, as determined by decreases in the colony numbers and densities. Quantification of colony formation by extracting the dye revealed a significant decrease in cells treated with $\mathrm{RA}$, resulting in a $70 \%$ decrease using $100 \mu \mathrm{M} \mathrm{RA}(\mathrm{F}=280.0, \mathrm{P}=0.0096$; one-way ANOVA). Fig. 1B indicates that this inhibitory effect was not due to cytotoxicity.

$R A$ suppresses the migratory and invasive abilities of MDA-MB231 cells. RA-untreated control MDA-MB231 cells migrated across a scratch wound region, leading to 51.6 and $82.5 \%$ healing at 12 and $18 \mathrm{~h}$, respectively. However, treatment with $100 \mu \mathrm{M}$ RA significantly inhibited wound migration by $35.91 \%$ at $12 \mathrm{~h}$ and $49.19 \%$ at $18 \mathrm{~h}$, when compared with that of control cells $(12 \mathrm{~h}, \mathrm{~F}=7.018, \mathrm{P}=0.0125 ; 18 \mathrm{~h}, \mathrm{~F}=30.37$, $\mathrm{P}=0.0001$; one-way ANOVA; Fig. 2A). Using a Transwell assay, RA suppressed the serum-induced migration and invasion in a dose-dependent manner, compared with that of the control cells, exhibiting decreases of 76.6 and $89.9 \%$ at $100 \mu \mathrm{M}$ $\mathrm{RA}$, respectively (migration, $\mathrm{F}=270.9, \mathrm{P}<0.0001$; invasion, $\mathrm{F}=605.2$, P<0.0001; one-way ANOVA; Fig. 2B). RA-untreated control cells invaded the Matrigel-coated scratch wound at levels of 57.5 and $84.3 \%$ at 12 and $24 \mathrm{~h}$, respectively, whereas treatment with $100 \mu \mathrm{M}$ RA decreased the invasion by 49.9 and $46.0 \%$ at $12 \mathrm{~h}$ and $24 \mathrm{~h}$, respectively $(12 \mathrm{~h}, \mathrm{~F}=9.970, \mathrm{P}=0.0044$; 24 h, F=17.27, P=0.0007; one-way ANOVA; Fig. 2C). In addition, invasion from 3D spheroids was also suppressed by RA treatment in a dose-dependent manner (3 days post-treatment, $\mathrm{T} 3, \mathrm{~F}=247.0, \mathrm{P}<0.0001 ; 5$ days post-treatment, T5, $\mathrm{F}=229.9$, $\mathrm{P}<0.0001$; one-way ANOVA; Fig. 2D). Together, these results indicated that RA exhibits potent anti-metastatic activity with no cytotoxicity in MDA-MB231 cells. 
A
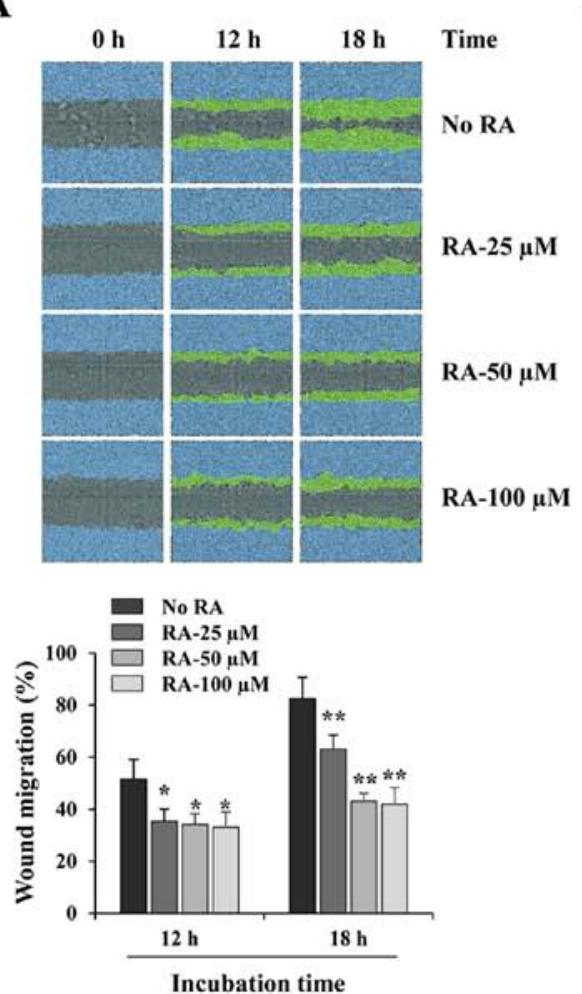

C
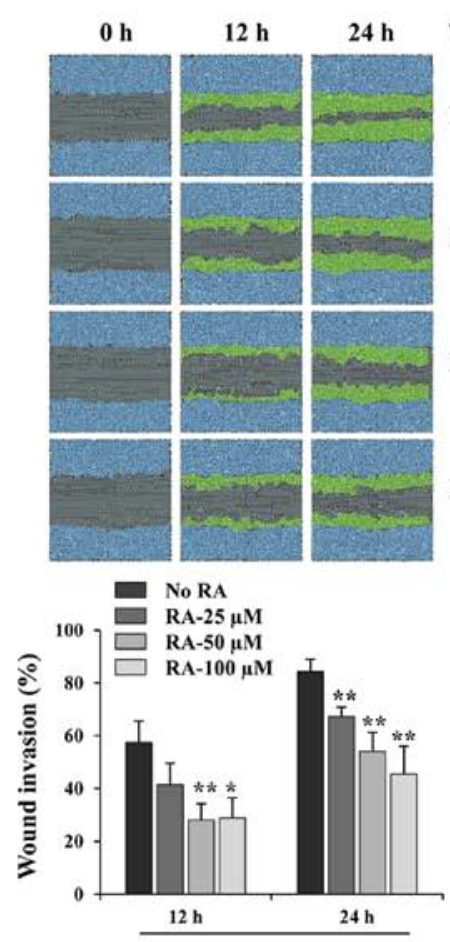

Incubation time
B
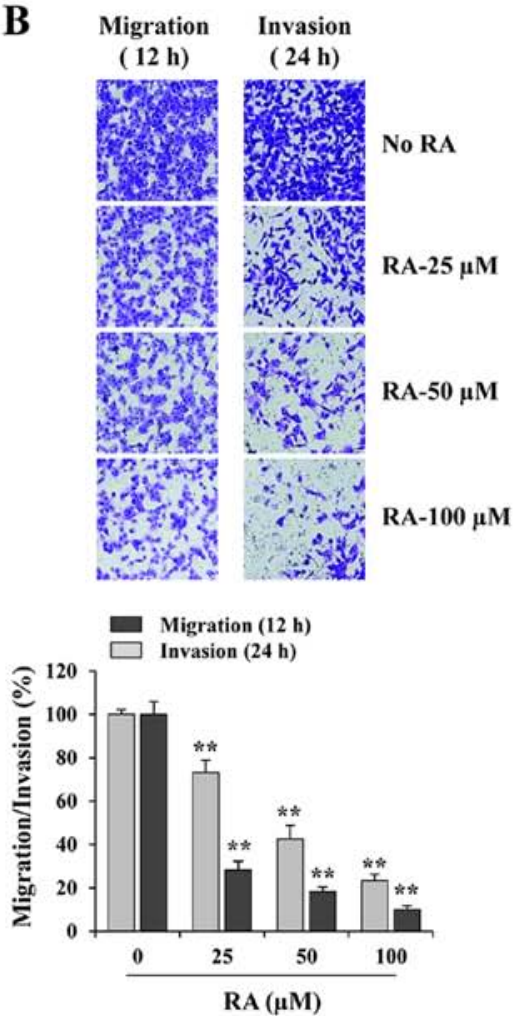

D
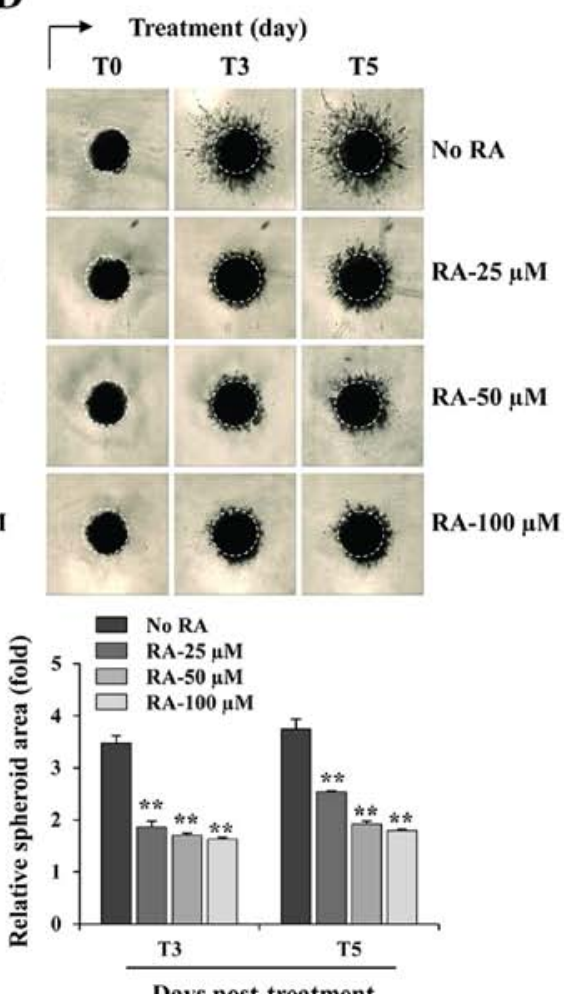

Days post-treatment

Figure 2. RA inhibits the migration and invasion of MDA-MB231 cells. (A) In a scratch migration assay, wound widths in RA-treated and -untreated cells were measured every $3 \mathrm{~h}$ following scratch wound formation using the IncuCyte Zoom. The relative wound migrations at 12 and $18 \mathrm{~h}$ were calculated based on the wound width at $0 \mathrm{~h}$ using ImageJ software, and are expressed as the mean $\pm \mathrm{SD}$ obtained from triplicate samples. (B) The migration and invasion of RA-treated and -untreated cells across Transwell membranes were measured following incubation for 12 and $24 \mathrm{~h}$, respectively. The number of cells in five random fields was determined using phase-contrast microscopy, and the relative migration and invasion were calculated and compared with RA-untreated control cells. The data are representative of three independent experiments and are expressed as the mean \pm SD. (C) In the scratch invasion assay, wound widths in RA-treated and -untreated cells were measured every $3 \mathrm{~h}$ following scratch wound formation using the IncuCyte Zoom. The relative wound invasions at 12 and $24 \mathrm{~h}$ were calculated based on the wound width at $0 \mathrm{~h}$ using ImageJ software, and are expressed as the mean $\pm \mathrm{SD}$ obtained from triplicate samples. (D) Cells were cultured as three-dimensional spheroids, treated with the indicated concentrations of RA and incubated further for 5 days. The images of stellate structural formations were captured at 3 and 5 days post-treatment, and the relative spheroid areas were measured using ImageJ software. Results are expressed as the mean \pm SD from triplicate samples. ${ }^{*} \mathrm{P}<0.05$ and ${ }^{* *} \mathrm{P}<0.01$ vs. untreated control. RA, rhaponticin; SD, standard deviation. 
A
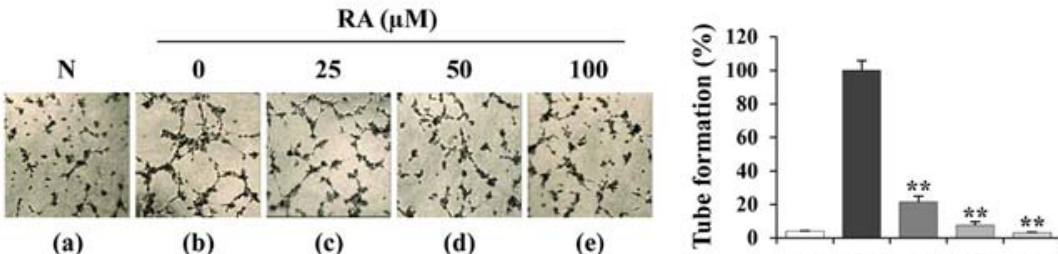

(a) (b) (c) (d) (e)

B

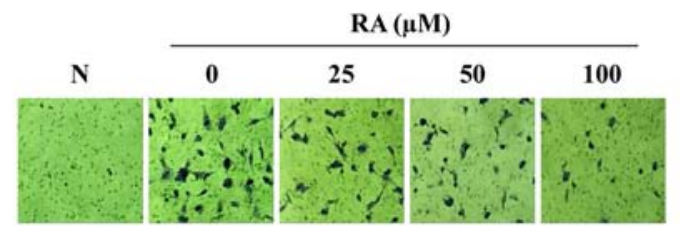

(a)

(b)

(c)

(d)

(e)

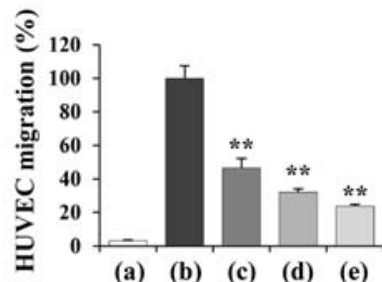

C
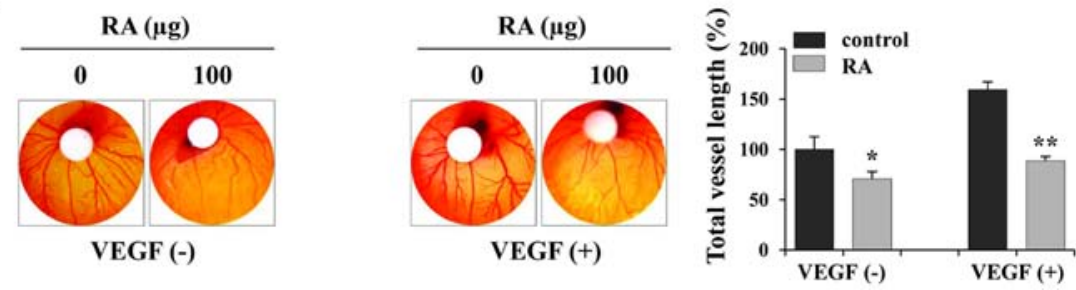

Figure 3. RA suppresses the angiogenic activity of HUVECs. (A) HUVECs were treated with or without the indicated concentrations of RA for 24 h, suspended in EGM-2, and seeded in basement membrane extract-coated wells. Following incubation for 4 h, capillary-like tube formation was measured. RA-untreated HUVECs in EBM-2 were used as a negative control. The number of tubes in triplicate samples was counted. (B) RA-treated or untreated HUVECs were suspended in EBM-2 and seeded into the upper chamber of the Transwell. The EGM-2-induced migration of HUVECs for $12 \mathrm{~h}$ was observed following staining with crystal violet solution ( $=5$ per group). (C) On ED day 6, RA (100 $\mu$ g) and VEGF (200 ng) in PBS (20 $\mu 1)$ were loaded onto filter discs and then carefully placed on the CAM. Following resealing the windows with adhesive tape, the eggs were incubated for 3 days. On ED day 9 , the vasculature in the eggs was photographed and the total vessel length ( $n=3$ per group) was measured by ImageJ software. The data are representative of three independent experiments and expressed as the mean $\pm \mathrm{SD}$. ${ }^{*} \mathrm{P}<0.05$ and ${ }^{* *} \mathrm{P}<0.01$ vs. RA-untreated control. RA, rhaponticin; HUVEC, human umbilical vein endothelial cell; EGM-2, endothelial cell growth medium-2; EBM-2, endothelial cell basal medium-2; N, negative control; ED, embryonic development; VEGF, vascular endothelial growth factor.

RA inhibits the angiogenic activities of HUVECs in vitro and in the CAM assay. To investigate the effects of RA on endothelial cells, the ability of RA-treated and -untreated HUVECs to form tube-like structures on Matrigel was assessed. To induce tube formation, the cells were suspended in EGM-2 containing angiogenic stimuli including endothelial growth factor (EGF), basic fibroblast growth factor (FGF) and VEGF. Fig. 3A indicates that HUVECs in EBM-2 (panel a) did not induce tube-like networks, whereas RA-untreated HUVECs in EGM-2 (panel b) induced almost complete tube formation. RA-treated HUVECs in EGM-2 (panels c-e) exhibited weak tube formation in a dose-dependent manner compared with RA-untreated HUVECs ( $\mathrm{F}=488.9, \mathrm{P}<0.0001$; one-way ANOVA). In addition, the ability of RA-treated and -untreated HUVECs to migrate across a Transwell membrane was investigated. Each group of HUVECs in EBM-2 was seeded in the upper chamber and then incubated for $12 \mathrm{~h}$ to allow downward migration to the lower chamber filled with EGM-2. Fig. 3B indicates that RA-untreated HUVECs migrated efficiently, whereas RA-treated HUVECs exhibited decreased migration in a dose-dependent manner to $23.6 \%$ of the control HUVECs at $100 \mu \mathrm{M}(\mathrm{F}=255.8, \mathrm{P}<0.0001$; one-way ANOVA). Using the CAM assay, spontaneous angiogenesis was observed on ED day 6, and topical application of RA suppressed spontaneous angiogenesis by $29.16 \%$ compared with the vehicle control on ED day 9 (Fig. 3C, left). Furthermore, VEGF induced a pronounced angiogenic response in terms of vessel length, thickness and sprouting, whereas RA at $100 \mu \mathrm{g}$ per embryo exhibited a significant inhibition of VEGF-induced angiogenesis (Fig. 3C, right), indicating that RA directly suppressed the angiogenesis of endothelial cells.

$R A$ decreases the production of angiogenesis-associated proteins under normoxic and hypoxic conditions in HT1080 cells. In the tumor microenvironment (TME), imbalances favoring angiogenic activators (e.g. VEGF, FGF, PDGFB and EGF) over inhibitors (e.g. thrombospondin-1, endostatin and angiostatin) activate the angiogenic switch that induces tumor vascularization, proliferation and metastasis $(23,24)$. Angiogenesis is therefore an important target for controlling solid tumors. To assess the effects of RA on the secretion of proand anti-angiogenic factors in HT1080 cells, the CM obtained from RA-untreated control and RA-treated HT1080 cells under normoxic and hypoxic conditions was analyzed using a Proteome Profiler Human Angiogenesis Array kit. Fig. 4A indicates that the levels of pro-angiogenic factors, including MMP-9, PTX-3, interleukin 8 (IL-8), VEGF and PIGF were significantly decreased in the RA-treated CM compared with the control CM 
A

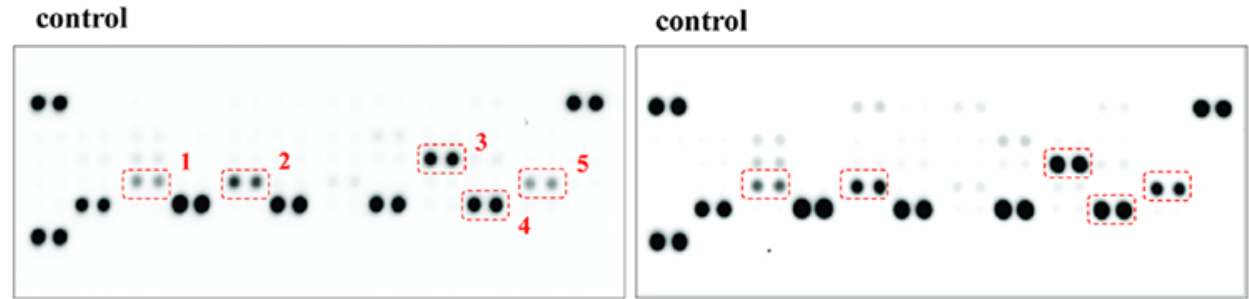

RA, $100 \mu \mathrm{M} \quad$ RA, $100 \mu \mathrm{M}$

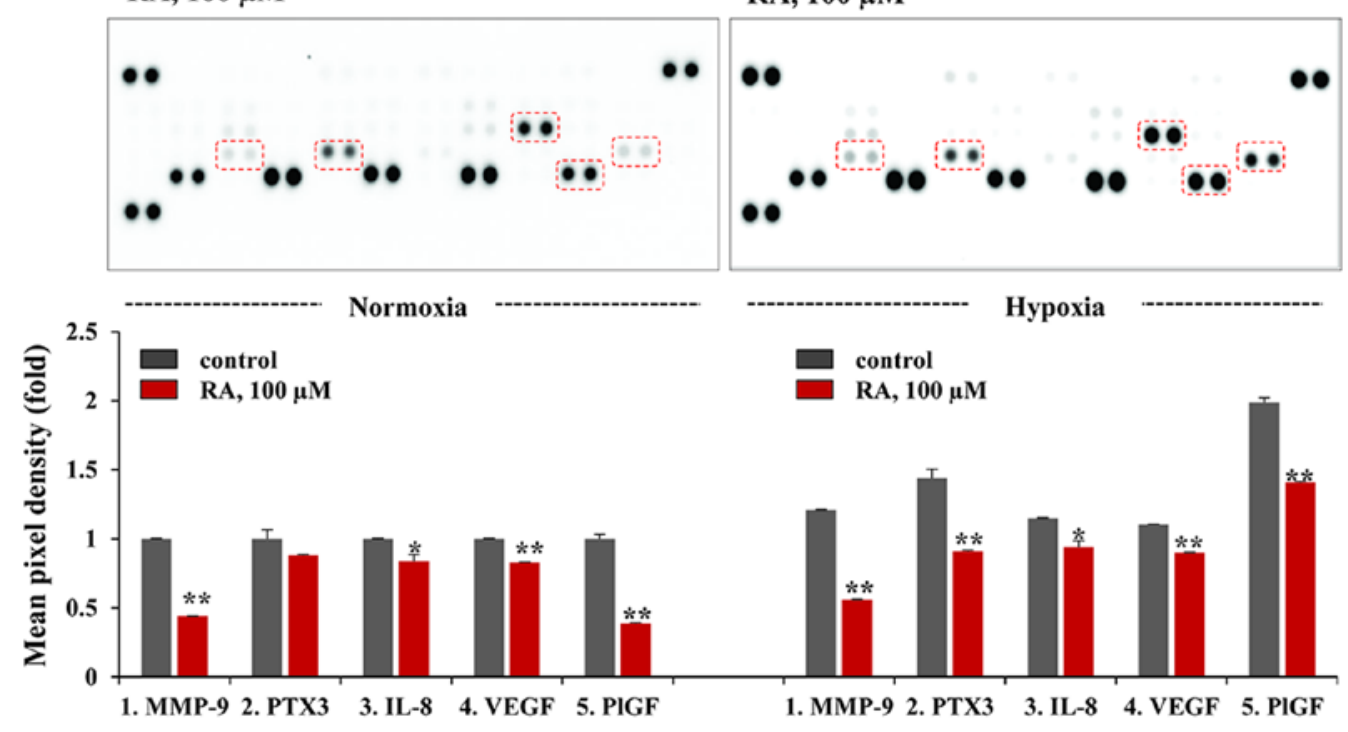

B

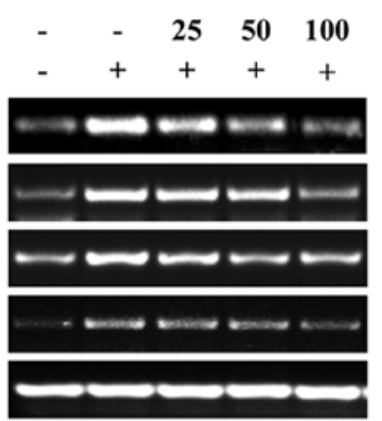

$\mathrm{RA}(\mu \mathrm{M})$
$\mathrm{CoCl}_{2}(200 \mu \mathrm{M})$
MMP-9
$\square$ (a), control
(c), $\mathrm{CoCl}_{2}+\mathrm{RA}-25$
(d), $\mathrm{CoCl}_{2}+\mathrm{RA}-50$

(e), $\mathrm{CoCl}_{2}+\mathrm{RA}-100$

PTX3

VEGF- $\alpha$

PIGF

GAPDH

(a) (b) (c) (d) (e)

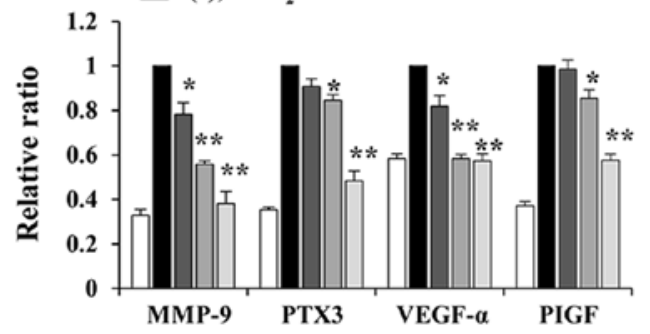

C

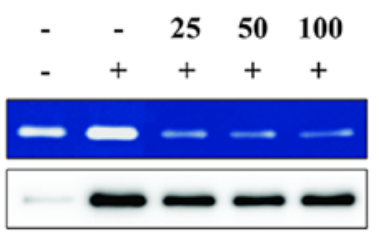

(a) (b) (c) (d) (e)
$\mathbf{R A}(\mu \mathrm{M})$

PMA (10 nM)

Zymography

Western blotting

Figure 4. RA decreases the production of pro-angiogenic proteins and MMP-9 activity of HT1080 cells. (A) Using a Proteome Profiler Human Angiogenesis Array kit, the levels of angiogenesis-associated proteins in $\mathrm{CM}$ were analyzed. The $\mathrm{CM}$ were obtained from RA-treated and -untreated cells incubated under normoxic $\left(20 \% \mathrm{O}_{2}\right)$ and hypoxic $\left(1 \% \mathrm{O}_{2}\right)$ conditions. The pixel intensity was measured using ImageJ software and the relative values are expressed as the mean \pm SD calculated from duplicate dots. The data are representative of two independent experiments. (B) Cells pretreated with or without RA for $12 \mathrm{~h}$ were stimulated with $\mathrm{CoCl}_{2}(200 \mu \mathrm{M})$ for $3 \mathrm{~h}$, and the mRNA levels of MMP-9, PTX-3, VEGF- $\alpha$ and PIGF were determined using the reverse transcriptionpolymerase chain reaction. The relative band intensities were analyzed using ImageJ software and calculated following normalization to GAPDH. Results are expressed as the mean \pm SD of two independent experiments. (C) The gelatinolytic activity of MMP-9 and the levels of MMP-9 in RA-treated and -untreated $\mathrm{CM}$ were measured using zymography and western blotting, respectively. The band intensities were analyzed using ImageJ software and expressed as the mean \pm SD of two independent experiments. ${ }^{*} \mathrm{P}<0.05$ and ${ }^{* *} \mathrm{P}<0.01$ vs. RA-untreated control. RA, rhaponticin; MMP, matrix metalloproteinase; CM, conditioned media; SD, standard deviation; PTX-3, pentraxin-related protein 3; VEGF, vascular endothelial growth factor; PIGF, placental growth factor; PMA, phorbol 12-myristate 13-acetate. 
A

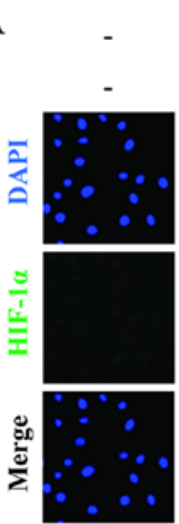

(a)

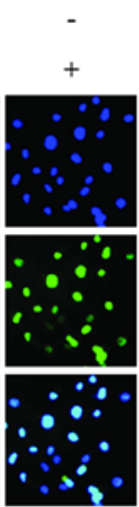

(b)

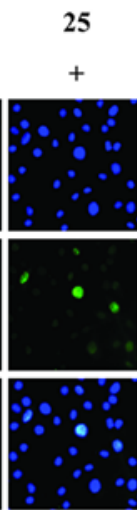

(c)

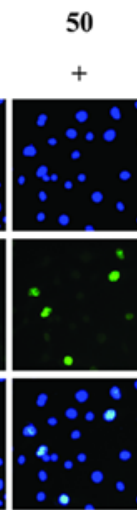

(d)

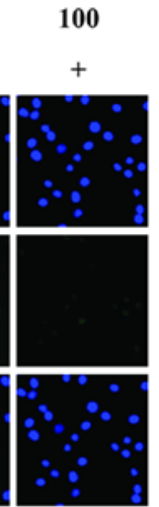

(e)
$\mathrm{RA}(\mu \mathrm{M})$

$\mathrm{CoCl}_{2}(200 \mu \mathrm{M})$

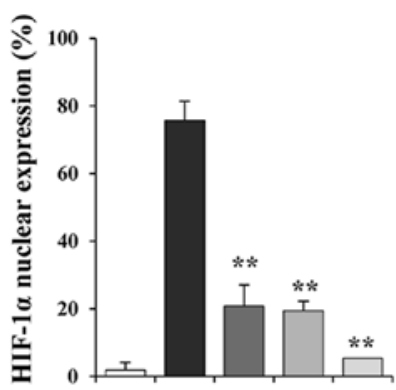

(a) (b) (c) (d) (e)

B

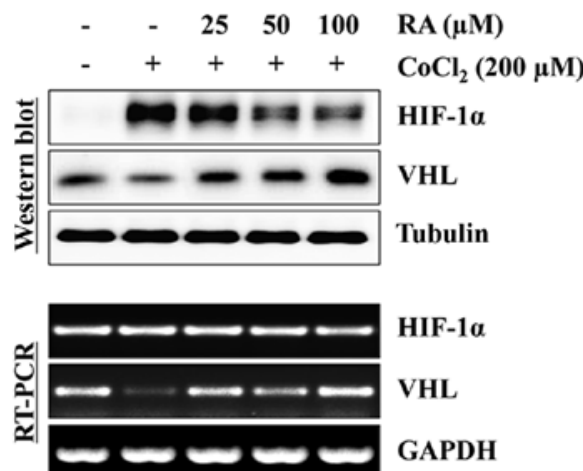

(a) (b) (c) (d) (e)
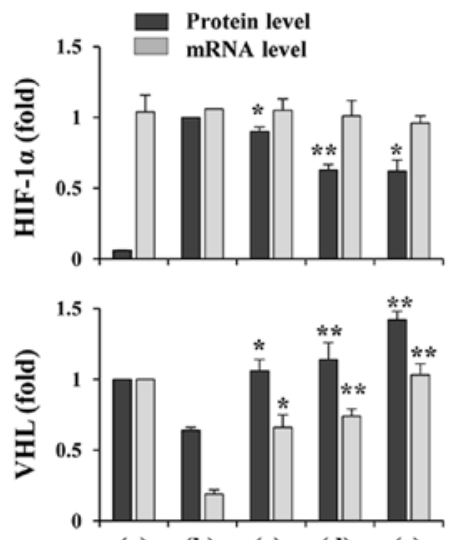

(a) (b) (c) (d) (e)

C

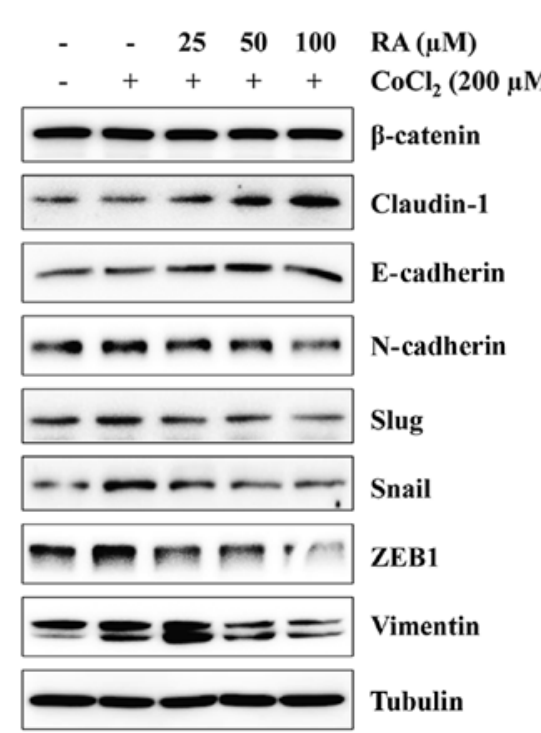

(a) (b) (c) (d) (e)
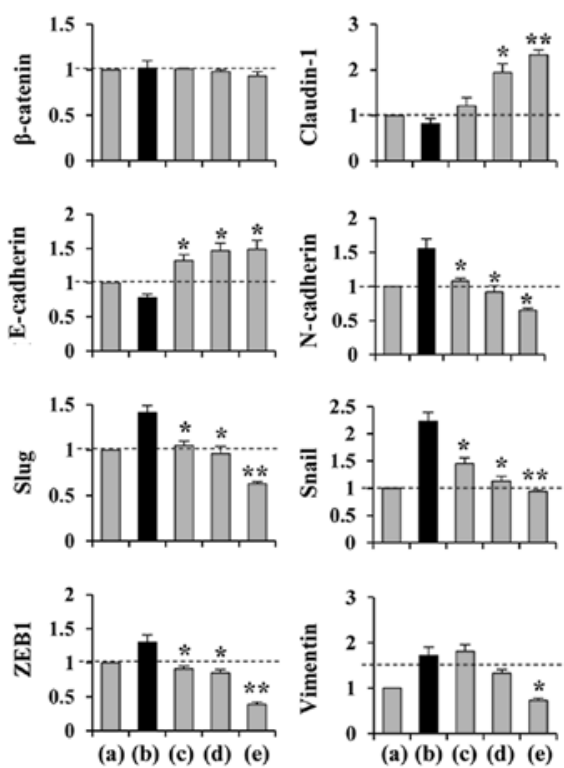

Figure 5. RA inhibits the nuclear expression and accumulation of HIF-1 $\alpha$, and regulates EMT-associated proteins in HT1080 cells under hypoxic conditions (A) Cells grown in glass-bottomed dishes were treated with RA for $12 \mathrm{~h}$ and then stimulated with $\mathrm{CoCl}_{2}(200 \mu \mathrm{M})$ to mimic hypoxic conditions. After $6 \mathrm{~h}$, nuclear HIF-1 $\alpha$ was visualized using fluorescence immunocytochemistry. DAPI was used for counterstaining nuclei. Results are presented as the mean \pm SD of five selected fields per sample, and are representative of three independent experiments. (B) The cells were incubated with or without RA for $12 \mathrm{~h}$ and then treated with $\mathrm{CoCl}_{2}(200 \mu \mathrm{M})$ for 3 or $6 \mathrm{~h}$. The mRNA and protein levels of HIF-1 $\alpha$ and VHL were detected using RT-PCR and western blotting, respectively. The relative band intensities were quantitated using ImageJ software following normalization to GAPDH and tubulin expression, respectively. (C) The cells were treated with or without RA for $12 \mathrm{~h}$ and then stimulated with $\mathrm{CoCl}_{2}(200 \mu \mathrm{M})$ for $24 \mathrm{~h}$. Cell lysates were subjected to western blotting against endothelial-mesenchymal transition-associated proteins. The relative band intensities were calculated using ImageJ software following normalization to tubulin expression. Results are expressed as the mean $\pm \mathrm{SD}$ of two independent experiments. ${ }^{*} \mathrm{P}<0.05$ and ${ }^{* *} \mathrm{P}<0.01$ vs. RA-untreated control. RA, rhaponticin; HIF, hypoxia-inducible factor; SD, standard deviation; VHL, von Hippel-Lindau protein; RT-PCR, reverse transcription-polymerase chain reaction; E-cadherin, epithelial cadherin; N-cadherin, neuronal cadherin; ZEB1, zinc finger E-box-binding homeobox 1. 
under normoxic conditions. Under hypoxic conditions, the levels of these pro-angiogenic factors were increased between 15 and 99\% compared with those under normoxic conditions, and RA treatment also decreased the levels of the pro-angiogenic factors. The transcriptional levels of MMP-9, PTX-3, VEGF- $\alpha$ and PIGF were also increased by $\mathrm{CoCl}_{2}$ stimulation, mimicking hypoxic conditions. However, the increase in the mRNA levels of these pro-angiogenic factors were significantly inhibited by RA treatment (MMP-9, F=99.31, P=0.0003; PTX-3, F=105.8, P=0.0003; VEGF- $\alpha, F=92.63, P=0.0004 ; P I G F, F=77.26, P=0.0005$; one-way ANOVA; Fig. 4B). Additionally, gelatin zymography and western blotting indicated that RA markedly suppressed the PMA-induced increase in the gelatinolytic activity of MMP-9 and secretion of MMP-9 into the CM of HT1080 cells (gelatin zymography, $\mathrm{F}=68.46$; $\mathrm{P}=0.0007$; western blotting, $\mathrm{F}=25.10$, $\mathrm{P}=0.0047$; one-way ANOVA; Fig. 4C). These results indicate that RA inhibits the angiogenic switch by suppression of angiogenic factors in tumor cells.

RA suppresses HIF-1 $\alpha$ accumulation and nuclear expression, and regulates EMT-associated proteins under hypoxic conditions in HT1080 cells. Since pro-angiogenic factors are downstream targets of HIF-1 $\alpha$, the effects of RA on the HIF-1 $\alpha$ nuclear expression and HIF-1 $\alpha$ accumulation under $\mathrm{CoCl}_{2}$ stimulation conditions, to mimic physiological hypoxia, were investigated. Fig. $5 \mathrm{~A}$ indicates that cells with nuclear HIF-1 $\alpha$ induced by $\mathrm{CoCl}_{2}$ treatment were decreased by RA treatment in a dose-dependent manner $(\mathrm{F}=213.4, \mathrm{P}<0.0001$; one-way ANOVA). Western blotting indicated that RA efficiently suppressed the $\mathrm{CoCl}_{2}$-induced accumulation of HIF-1 $\alpha$ protein in a dose-dependent manner $(\mathrm{F}=33.33, \mathrm{P}=0.0027$; one-way ANOVA). However, the mRNA levels of HIF-1 $\alpha$ were not influenced by RA treatment, suggesting that RA did not affect the transcription of the HIF-1 $\alpha$ gene. In addition, RA significantly increased the VHL expression at the mRNA and protein levels, leading to the rapid degradation of HIF-1 $\alpha$ (VHL mRNA, $\mathrm{F}=54.24, \mathrm{P}=0.0011$; $\mathrm{VHL}$ protein, $\mathrm{F}=33.58, \mathrm{P}=0.0027$; one-way ANOVA; Fig. 5B). These results indicated that RA decreased the production of angiogenesis-associated proteins via suppression of HIF-1 $\alpha$ stability and induction of HIF-1 $\alpha$ degradation. Hypoxia-induced HIF-1 $\alpha$ stabilization promotes EMT in a number of types of cancer, and is associated with metastasis and resistance to chemo- and radiotherapy $(25,26)$. Several transcription factors, including Slug, Snail and Twist, drive the EMT process and cause the loss of cell-cell junctions, thereby allowing migration and dissemination of tumor cells (27). Since RA efficiently decreased hypoxia-induced HIF-1 $\alpha$ accumulation, the effect of RA on the expression of EMT-associated proteins under hypoxic conditions was investigated. As presented in Fig. $5 \mathrm{C}, \mathrm{CoCl}_{2}$ stimulation significantly increased mesenchymal markers, including $\mathrm{N}$-cadherin, Slug, Snail, ZEB1 and vimentin, whereas it slightly decreased claudin-1 and E-cadherin. In RA-treated cells, the levels of mesenchymal markers were significantly decreased compared with those in RA-untreated control cells, whereas the levels of claudin-1 and E-cadherin were increased in a dose-dependent manner (claudin-1, $\mathrm{F}=40.46, \mathrm{P}=0.0019$; E-cadherin, $\mathrm{F}=22.28$, $\mathrm{P}=0.0059 ; \mathrm{N}$-cadherin, $\mathrm{F}=38.61, \mathrm{P}=0.0021$; Slug, $\mathrm{F}=52.39$, $\mathrm{P}=0.0011$; Snail, $\mathrm{F}=55.40, \mathrm{P}=0.0010 ; \mathrm{ZEB} 1, \mathrm{~F}=65.04$, $\mathrm{P}=0.0008$; vimentin, $\mathrm{F}=30.27, \mathrm{P}=0.0033$; one-way ANOVA;
Fig. 5C), suggesting that RA regulates EMT-associated proteins via suppression of the HIF-1 signaling pathway.

\section{Discussion}

Carcinogenesis, also called oncogenesis or tumorigenesis, which involves the formation of a cancer, is a complicated and multistep process consisting of the stages of initiation, promotion and progression (28). The majority of human cancer types exhibit various hallmarks, including sustained proliferation, evasion of tumor suppressors, resistance to cell death, angiogenesis, escape from the immune response, inflammation, angiogenesis, invasion and metastasis (29). Previous studies have identified that carcinogenesis occurs by close interaction of cancer cells with the surrounding ECM and neighboring normal stromal cells. Cancer cells secrete growth factors, chemokines and cytokines, which efficiently recruit stromal cells, vascular cells and immune cells in the TME. In turn, these recruited cells also affect cancer cells by releasing growth-promoting signals and providing a suitable environment for tumor progression and metastasis, indicating that the TME is not simply a bystander, but an important potential therapeutic target for cancer treatment (30-32). Consistent with this possibility, several clinical and preclinical studies that primarily target the TME for managing metastatic cancer have been conducted. Therapeutic strategies include targeting the tumor vasculature, cancer-associated inflammation, the communication between tumor cells and the TME, and the hypoxia in the TME $(33,34)$. Angiogenesis during normal physiological conditions, such as embryonic development, tissue regeneration and wound healing, occurs by a regulated process to form well-organized vascular networks. In contrast, in pathological conditions such as ocular neovascularization in diabetes, arthritis and cancer, the balance between the pro- and anti-angiogenic factors shifts in favor of the pro-angiogenic factors, leading to the formation of a disorganized vascular network (35). Blood vessels within tumors act as a pathway to provide sufficient oxygen and nutrients, to eliminate waste metabolites, and to facilitate cellular entry into the circulation, thus promoting tumor growth and metastasis $(36,37)$.

Hypoxia is common in a majority of malignant tumors and is important for facilitating rapid formation of blood vessels, by increasing the proliferation, migration and organization of endothelial cells into new tubular structures. In addition, hypoxia in the TME increases tumor cell survival, metastasis, the EMT and resistance to cell death (31). The transcription factor HIF- $1 \alpha$ is primarily involved in these processes, so targeting the HIF-1 pathway is considered to be a promising strategy to control tumor growth, improve the efficacy of treatment and prolong the survival of patients with cancer $(38,39)$. Consistent with these possibilities, inhibition of HIF-1 activity using an antisense oligonucleotide was an effective and safe treatment of metastatic cancer cells in Phase I clinical trials $(40,41)$. In addition, phytochemicals including decursin, decursinol, curcumin, resveratrol and genistein have been reported to exhibit anti-angiogenic effects in various types of cancer (42-44).

RA isolated from a number of medicinal herbs has been identified to possess various pharmacological effects, including antioxidant, anti-thrombotic, anti-allergic and 
vasorelaxant activities (12-19,45). In addition, antitumor activities using PEGylated liposomal RA and RA containing a stilbene moiety were identified to exhibit growth-inhibiting and apoptosis-inducing activities (46). Notably, rhapontigenin (Rha), an aglycone form of RA, has been identified to impede cancer progression by disrupting EMT and angiogenesis via inhibition of transforming growth factor- $\beta$-induced Snail expression (47). In addition, Rha suppressed the migration and invasion of MDA-MB231 breast cancer cells by inhibiting phosphoinositide 3-kinase-dependent Rac1 signaling, and exhibited an anti-angiogenic effect in hypoxic PC-3 prostate cancer cells by inhibiting HIF-1 $\alpha$ accumulation $(48,49)$. Since it is known that the aglycone form did not always exhibit the same pharmacological action as the glycone form, the present study is therefore the first report to show the anti-metastatic and anti-angiogenic activities of RA and its underlying molecular mechanisms using both in vitro and in ovo systems.

In the present study, it was identified that RA at noncytotoxic concentrations efficiently suppressed the metastatic ability of MDA-MB231 cells, including anchorage-dependent colony formation, migration and invasion. In addition, it was also observed that RA treatment decreased the ability of HUVECs to form a vascular network and migrate through the Transwell. Furthermore, RA treatment in the CAM assay significantly inhibited angiogenesis in normal and VEGF-stimulation conditions, indicating that RA directly regulates tumor cells and endothelial cells to limit tumor progression. In HT1080 cells, RA treatment under normoxic and hypoxic conditions inhibited the production of proangiogenic factors, including MMP-9, PTX-3, IL-8, VEGF and PIGF, which enhanced proliferation, migration, sprouting, permeability and resistance to apoptosis of endothelial cells. In addition, RA suppressed the PMA-induced increase of MMP-9 proteolytic activity, reinforcing the inhibitory effects of RA on metastasis and angiogenesis. Consistent with these results, RA inhibited hypoxia-induced HIF-1 $\alpha$ accumulation and nuclear expression via enhancing HIF-1 $\alpha$ degradation by increasing VHL expression, indicating that RA acts as an important regulator of the HIF-1 pathway. Further investigation of the function of kinases which are downstream targets of HIF-1, including Akt and mTOR, on the RA-induced anti-metastatic and anti-angiogenic activities using short interfering RNA.

EMT is a downstream target of the HIF-1 pathway, in which epithelial cells acquire the phenotype of mesenchymal cells via disruption of cell-cell interactions and loss of the tight junction (TJ) barrier, thereby leading to the dissemination of tumor cells from the primary tumor (50). Claudin-1, a transmembrane protein of the TJ, has long been postulated to be a tumor suppressor in breast cancer, because it is downregulated in breast cancers compared with normal breast epithelia. In addition, the loss of claudin-1 has been associated with increased recurrence, shorter survival and enhanced invasiveness (51). In contrast, it was identified previously that overexpression of claudin-1 in the colon, colorectal area and in melanomas increased cell invasion, indicating that claudin-1 was able to promote or suppress tumor progression (52). In the present study, RA significantly increased the levels of E-cadherin and claudin-1 in HT1080 cells under hypoxic conditions, whereas it decreased the levels of N-cadherin, Slug, Snail, ZEB-1 and vimentin, which are positive regulators of EMT.
In summary, RA inhibited the metastatic potential of malignant cancer cells, including MDA-MB231 and HT1080 cells, by inhibiting the HIF-1 pathway and regulating the EMT-associated proteins. In addition, RA efficiently decreased the angiogenic activities of endothelial cells. Taken together, these results indicate that RA may be a potent anticancer agent, which could be used to treat highly metastatic malignant human cancers. Currently, to verify the in vivo effectiveness of RA, we are investigating whether repeated oral administration of RA is able to suppress the metastasis of malignant cancer cells. In addition, assessment of the safety of RA during experimental periods is also underway.

\section{Acknowledgements}

Not applicable.

\section{Funding}

The present study was supported by the Korea Institute of Oriental Medicine (KIOM) from the Ministry of Science, ICT and Future Planning (MSIP), Republic of Korea (grant no. K17281).

\section{Availability of data and materials}

All data generated or analyzed during this study are included in this published article.

\section{Authors' contributions}

AK and JYM conceived and designed the experiments. AK performed the experiments, analyzed the data, and wrote the manuscript. All authors reviewed the results and approved the final version of the manuscript.

\section{Ethics approval and consent to participate}

Not applicable.

\section{Patient consent for publication}

Not applicable.

\section{Competing interests}

The authors declare that they have no competing interests.

\section{References}

1. Valastyan S and Weinberg RA: Tumor metastasis: Molecular insights and evolving paradigms. Cell 147: 275-292, 2011.

2. Leber MF and Efferth T: Molecular principles of cancer invasion and metastasis (review). Int J Oncol 34: 881-895, 2009.

3. Alizadeh AM, Shiri S and Farsinejad S: Metastasis review: From bench to bedside. Tumour Biol 35: 8483-8523, 2014.

4. Patel LR, Camacho DF, Shiozawa Y, Pienta KJ and Taichman RS Mechanisms of cancer cell metastasis to the bone: A multistep process. Future Oncol 7: 1285-1297, 2011.

5. Guan X: Cancer metastases: Challenges and opportunities. Acta Pharm Sin B 5: 402-418, 2015.

6. Vasaturo F, Solai F, Malacrino C, Nardo T, Vincenzi B, Modesti M and Scarpa S: Plasma levels of matrix metalloproteinases 2 and 9 correlate with histological grade in breast cancer patients. Oncol Lett 5: 316-320, 2013. 
7. Deryugina EI and Quigley JP: Tumor angiogenesis: MMP-mediated induction of intravasation- and metastasissustaining neovasculature. Matrix Biol 44-46: 94-112, 2015.

8. Kessenbrock K, Plaks V and Werb Z: Matrix metalloproteinases: Regulators of the tumor microenvironment. Cell 141: 52-67, 2010

9. Wilson WR and Hay MP: Targeting hypoxia in cancer therapy. Nat Rev Cancer 11: 393-410, 2011.

10. Wigerup C, Påhlman S and Bexell D: Therapeutic targeting of hypoxia and hypoxia-inducible factors in cancer. Pharmacol Ther 164: 152-169, 2016.

11. Vaupel P and Mayer A: Hypoxia in cancer: Significance and impact on clinical outcome. Cancer Metastasis Rev 26: 225-239, 2007.

12. Yoo MY, Oh KS, Lee JW, Seo HW, Yon GH, Kwon DY, Kim YS, Ryu SY and Lee BH: Vasorelaxant effect of stilbenes from rhizome extract of rhubarb (Rheum undulatum) on the contractility of rat aorta. Phytother Res 21: 186-189, 2007

13. Moon MK, Kang DG, Lee JK, Kim JS and Lee HS: Vasodilatory and anti-inflammatory effects of the aqueous extract of rhubarb via a NO-cGMP pathway. Life Sci 78: 1550-1557, 2006.

14. Matsuda H, Tewtrakul S, Morikawa T and Yoshikawa M: Anti-allergic activity of stilbenes from Korean rhubarb (Rheum undulatum L.): Structure requirements for inhibition of antigen-induced degranulation and their effects on the release of TNF-alpha and IL-4 in RBL-2H3 cells. Bioorg Med Chem 12: 4871-4876, 2004

15. Song JH, Yang TC, Chang KW, Han SK, Yi HK and Jeon JG: In vitro anti-cariogenic activity of dichloromethane fraction from Rheum undulatum L. root. Arch Pharm Res 29: 490-496, 2006.

16. Matsuda H, Morikawa T, Toguchida I, Park JY, Harima S and Yoshikawa M: Antioxidant constituents from rhubarb: Structural requirements of stilbenes for the activity and structures of two new anthraquinone glucosides. Bioorg Med Chem 9: 41-50, 2001.

17. Ko SK, Lee SM and Whang WK: Anti-platelet aggregation activity of stilbene derivatives from Rheum undulatum. Arch Pharm Res 22: 401-403, 1999.

18. Tao L, Cao J, Wei W, Xie H, Zhang M and Zhang C: Protective role of rhapontin in experimental pulmonary fibrosis in vitro and in vivo. Int Immunopharmacol 47: 38-46, 2017

19. Wei W, Wang L, Zhou K, Xie H, Zhang M and Zhang C: Rhapontin ameliorates colonic epithelial dysfunction in experimental colitis through SIRT1 signaling. Int Immunopharmaco 42: 185-194, 2017.

20. Chen J, Ma M, Lu Y, Wang L, Wu C and Duan H: Rhaponticin from rhubarb rhizomes alleviates liver steatosis and improves blood glucose and lipid profiles in KK/Ay diabetic mice. Planta Med 75: 472-477, 2009.

21. Kim A, Im M, Yim NH, Jung YP and Ma JY: Aqueous extract of Bambusae Caulis in Taeniam inhibits PMA-induced tumor cell invasion and pulmonary metastasis: Suppression of NF- $\mathrm{BB}$ activation through ROS signaling. PLoS One 8: e78061, 2013.

22. Kim A, Im M, Gu MJ and Ma JY: Ethanol extract of Lophatheri Herba exhibits anti-cancer activity in human cancer cells by suppression of metastatic and angiogenic potential. Sci Rep 6: $36277,2016$.

23. Gupta MK and Qin RY: Mechanism and its regulation of tumorinduced angiogenesis. World J Gastroenterol 9: 1144-1155, 2003.

24. Vaupel P: The role of hypoxia-induced factors in tumor progression. Oncologist 9 (Suppl 5): 10-17, 2004.

25. Shang Y, Cai X and Fan D: Roles of epithelial-mesenchymal transition in cancer drug resistance. Curr Cancer Drug Targets 13: 915-929, 2013

26. Polyak K and Weinberg RA: Transitions between epithelial and mesenchymal states: Acquisition of malignant and stem cell traits. Nat Rev Cancer 9: 265-273, 2009.

27. Garg M: Epithelial-mesenchymal transition - activating transcription factors - multifunctional regulators in cancer. World J Stem Cells 5: 188-195, 2013.

28. Weinberg RA: Oncogenes, antioncogenes, and the molecular bases of multistep carcinogenesis. Cancer Res 49: 3713-3721, 1989.

29. Colotta F, Allavena P, Sica A, Garlanda C and Mantovani A: Cancer-related inflammation, the seventh hallmark of cancer: Links to genetic instability. Carcinogenesis 30: 1073-1081, 2009.

30. Mbeunkui F and Johann DJ Jr: Cancer and the tumor microenvironment: A review of an essential relationship. Cancer Chemother Pharmacol 63: 571-582, 2009.

31. 31. Finger EC and Giaccia AJ: Hypoxia, inflammation, and the tumor microenvironment in metastatic disease. Cancer Metastasis Rev 29: 285-293, 2010
32. Li H, Fan X and Houghton J: Tumor microenvironment: The role of the tumor stroma in cancer. J Cell Biochem 101: 805-815, 2007

33. Cairns R, Papandreou I and Denko N: Overcoming physiologic barriers to cancer treatment by molecularly targeting the tumor microenvironment. Mol Cancer Res 4: 61-70, 2006.

34. Joyce JA: Therapeutic targeting of the tumor microenvironment. Cancer Cell 7: 513-520, 2005 .

35. Carmeliet P and Jain RK: Angiogenesis in cancer and other diseases. Nature 407: 249-257, 2000

36. Chang $\mathrm{C}$ and Werb Z: The many faces of metalloproteases: Cell growth, invasion, angiogenesis and metastasis. Trends Cell Biol 11: S37-S43, 2001

37. Rak JW, St Croix BD and Kerbel RS: Consequences of angiogenesis for tumor progression, metastasis and cancer therapy. Anticancer Drugs 6: 3-18, 1995.

38. Semenza GL: HIF-1 and tumor progression: Pathophysiology and therapeutics. Trends Mol Med 8 (Suppl): S62-S67, 2002.

39. Semenza GL: Hypoxia-inducible factors: Mediators of cancer progression and targets for cancer therapy. Trends Pharmacol Sci 33: 207-214, 2012.

40. Jeong W, Rapisarda A, Park SR, Kinders RJ, Chen A, Melillo G, Turkbey B, Steinberg SM, Choyke P, Doroshow JH, et al: Pilot trial of EZN-2968, an antisense oligonucleotide inhibitor of hypoxiainducible factor-1 alpha (HIF-1 $\alpha$ ), in patients with refractory solid tumors. Cancer Chemother Pharmacol 73: 343-348, 2014.

41. Patnaik A, Chiorean EG, Tolcher A, Papadopoulos K, Beeram M, Kee D, Waddell M, Gilles E and Buchbinder A: EZN-2968, a novel hypoxia-inducible factor-1 alpha (HIF-1 $\alpha$ ) messenger ribonucleic acid (mRNA) antagonist: Results of a phase I, pharmacokinetic (PK), dose escalation study of daily administration in patients (pts) with advanced malignancies. J Clin Oncol 27: 2564, 2009.

42. Son SH, Kim MJ, Chung WY, Son JA, Kim YS, Kim YC, Kang SS, Lee SK and Park KK: Decursin and decursinol inhibit VEGF-induced angiogenesis by blocking the activation of extracellular signal-regulated kinase and c-Jun N-terminal kinase. Cancer Lett 280: 86-92, 2009.

43. Yoysungnoen $\mathrm{P}$, Wirachwong $\mathrm{P}$, Bhattarakosol $\mathrm{P}, \mathrm{Niimi} \mathrm{H}$ and Patumraj S: Effects of curcumin on tumor angiogenesis and biomarkers, COX-2 and VEGF, in hepatocellular carcinoma cellimplanted nude mice. Clin Hemorheol Microcirc 34: 109-115, 2006

44. Su SJ, Yeh TM, Chuang WJ, Ho CL, Chang KL, Cheng HL, Liu HS, Cheng HL, Hsu PY and Chow NH: The novel targets for anti-angiogenesis of genistein on human cancer cells. Biochem Pharmacol 69: 307-318, 2005

45. Jo SP, Kim JK and Lim YH: Antihyperlipidemic effects of rhapontin and rhapontigenin from rheum undulatum in rats fed a high-cholesterol diet. Planta Med 80: 1067-1071, 2014.

46. Sun Y and Zhao Y: Enhanced pharmacokinetics and anti-tumor efficacy of PEGylated liposomal rhaponticin and plasma protein binding ability of rhaponticin. J Nanosci Nanotechnol 12: 7677-7684, 2012

47. Yeh YH, Wang SW, Yeh YC, Hsiao HF and Li TK: Rhapontigenin inhibits TGF- $\beta$-mediated epithelial-mesenchymal transition via the PI3K/AKT/mTOR pathway and is not associated with HIF-1a degradation. Oncol Rep 35: 2887-2895, 2016.

48. Kim JS, Kang CG, Kim SH and Lee EO: Rhapontigenin suppresses cell migration and invasion by inhibiting the PI3Kdependent Racl signaling pathway in MDA-MB-231 human breast cancer cells. J Nat Prod 77: 1135-1139, 2014

49. Jung DB, Lee HJ, Jeong SJ, Lee HJ, Lee EO, Kim YC, Ahn KS, Chen CY and Kim SH: Rhapontigenin inhibited hypoxia inducible factor 1 alpha accumulation and angiogenesis in hypoxic PC-3 prostate cancer cells. Biol Pharm Bull 34: 850-855, 2011.

50. Martin TA and Jiang WG: Loss of tight junction barrier function and its role in cancer metastasis. Biochim Biophys Acta 1788: 872-891, 2009

51. Morohashi S, Kusumi T, Sato F, Odagiri H, Chiba H, Yoshihara S, Hakamada K, Sasaki M and Kijima H: Decreased expression of claudin-1 correlates with recurrence status in breast cancer. Int J Mol Med 20: 139-143, 2007.

52. Dhawan P, Singh AB, Deane NG, No Y, Shiou SR, Schmidt C, Neff J, Washington MK and Beauchamp RD: Claudin-1 regulates cellular transformation and metastatic behavior in colon cancer. J Clin Invest 115: 1765-1776, 2005.

This work is licensed under a Creative Commons Attribution-NonCommercial-NoDerivatives 4.0 International (CC BY-NC-ND 4.0) License. 